\title{
Desain dan Analisis Algoritma Penyelesaian Permasalahan Penugasan Bersyarat dengan Representasi Bipartite Graph
}

\author{
Muhammad Izzuddin, Arya Yudhi Wijaya, Rully Soelaiman \\ Jurusan Teknik Informatika, Fakultas Teknologi Informasi, Institut Teknologi Sepuluh Nopember (ITS) \\ Jl. Arief Rahman Hakim, Surabaya 60111 Indonesia \\ e-mail: rully@is.its.ac.id
}

\begin{abstract}
Abstrak-Permasalahan dalam penelitian ini adalah permasalahan penugasan bersyarat dimana terdapat beberapa pekerjaan dan beberapa orang pekerja. Setiap pekerjaan harus dilakukan oleh semua orang yang ada serta setiap orang memiliki waktu yang dibutuhkan tersendiri dalam menyelesaikan pekerjaan tersebut. Setiap orang hanya dapat mengerjakan sebuah pekerjaan dan sebuah pekerjaan hanya dapat dikerjakan oleh satu orang dalam satu waktu. Pekerjaan yang dimaksud juga bersifat independen dalam artian dapat dilakukan kapanpun oleh setiap orang. Semua orang juga dapat berhenti kapanpun untuk melakukan sebuah pekerjaan tersebut.

Penelitian ini akan mengimplementasikan metode pencarian maximum-size matching pada sebuah bipartite graph yang mengacu pada permasalahan penugasan bersyarat. Dalam penelitan ini dibahas algoritma Hopcroft-Karp untuk menyelesaikan permasalahan penugasan bersyarat tersebut dengan menggunakan bahasa pemrograman $\mathrm{C}++$.

Dari serangkaian proses penelitian yang telah dilakukan, didapatkan kesimpulan bahwa algoritma yang dirancang sesuai dengan permasalahan ini dipengaruhi secara kuadratik baik oleh jumlah pekerjaan ataupun pekerjanya.
\end{abstract}

Kata Kunci-Algoritma Hopcroft-Karp, Grafik Bipartite, Masalah Penugasan Bersyarat, Perfect Matching, Teori Grafik

\section{PENDAHULUAN}

Dalam teori grafik, permasalahan penugasan bersyarat membahas bagaimana menemukan susunan pemberian tugas atau pekerjaan pada pekerja agar sebuah pekerjaan tersebut dapat dilakukan dengan seoptimal mingkin dengan beberapa konstrain permasalahan yang ada. Pemasalahan penugasan bersyarat yang diangkat dalam penelitian ini diambil dari persoalan SPOJ Klasik 6819 yang berjudul Yet Another Assignment Problem dengan kode soal ASSIGN5. Permasalahan tersebut akan diselesakan dengan pendekatan pencarian Maximum-size Matching pada sebuah birpartite graph.

Pada permasalahan Yet Another Assignment Problem, terdapat beberapa pekerjaan dan beberapa orang pekerja yang akan mengerjakan pekerjaan tersebut. Setiap pekerjaan harus dilakukan oleh semua orang yang ada serta setiap orang memiliki waktu yang dibutuhkan tersendiri dalam menyelesaikan pekerjaan tersebut. Setiap orang hanya dapat mengerjakan sebuah pekerjaan dan sebuah pekerjaan hanya dapat dikerjakan oleh satu orang dalam satu waktu. Pekerjaan yang dimaksud juga bersifat independen dalam artian dapat dilakukan kapanpun oleh setiap orang. Semua orang juga dapat berhenti kapanpun untuk melakukan sebuah pekerjaan tersebut.

Diberikan $m$ pekerjaan dan $n$ pekerja, serta $m$ baris kelompok bilangan. Setiap baris $i$ berisi $n$ buah bilangan dimana bilangan ke $j$-nya adalah $A_{\mathrm{i} j}$ yang berarti teman ke- $j$ harus melakukan pekerjaan $i$ selama $A_{\mathrm{i} j}$ menit. Diminta untuk mencari waktu minimal yang diperlukan untuk melakukan semua pekerjaan tersebut beserta susunan penugasan pada menit pertama yang mungkin terjadi.

\section{TINJAUAN PUSTAKA}

\section{A. Bipartite Graph}

Bipartite graph merupakan grafik spesial yang vertex-nya dapat dibagi menjadi dua himpunan vertex $X$ dan $Y$ dimana pada setiap himpunan vertex-nya, tidak ada vertex yang saling bertetangga. Dalam kasus khusus, bipartite graph dapat membentuk sebuah complete bipartite graph. Complete bipartite graph adalah sebuah bipartite graph dimana tiap vertex pada satu himpunan, bersinggungan dengan semua vertex pada himpunan yang lainnya.

\section{B. Matching}

Sebuah matching pada grafik $G=(V, E)$ adalah sebuah himpunan edge $M \subseteq E$ dimana tidak ada edge yang saling bersentuhan di dalam $M$. Untuk setiap matching $M$ pada grafik $G=\left(V_{s} E\right)$, kumpulan edge $e \in M$ dinamakan matched edge, sedangkan kumpulan edge $e \in E-M$ dinamakan unmatched edge. Sebuah vertex dikatakan matched vertex apabila vertex tersebut besinggungan dengan matched edge pula. Sebaliknya unmatched vertex adalah vertex yang tidak bersinggungan dengan matched edge. Tiap matched vertex $v$ memiliki sebuah mate atau pasangan yang terletak pada endpoint dari matched edge yang bersinggungan dengan $v$. Sebuah matching dapat dikatakan sebagai perfect matching apabila semua edge pada matching $M$ dalam grafik $G=(V, E)$ mencakup setiap vertex dalam grafik atau tiap vertex dalam $V$ bersinggungan dengan tepat satu $e d g e$ pada $M$. Kardinalitas dari matching $M$ adalah banyaknya $e d g e$ pada $M$ dan biasa dinotasikan dengan $|M|$. Maximum-size matching adalah sebuah matching $M$ pada grafik $G=(V, E)$ yang kardinalitasnya tidak dapat dinaikkan lagi atau memiliki $|M|$ terbesar. 
Bipartite matching merupakan kasus matching khusus yang melibatkan struktur bipartite graph didalamnya. Bipartite graph $G=(X \cup Y, E)$ dapat memiliki sebuah complete matching dengan kardinalitas $\min \left\{|X|_{v}|Y|\right\}$.

\section{Algoritma Hopcroft-Karp}

Algoritma Hopcroft-Karp adalah algoritma yang memerlukan bipartite graph sebagai masukannya dan menghasilkan maximum-size matching didalam grafik tersebut sebagai keluarannya. Algoritma ini ditemukan John Hopcroft and Richard Karp pada tahun 1973.

Sebagian besar ide dasar dari algoritma ini hampir sama dengan teknik inverting augmenting path dalam mencari maximum-size matching, hanya saja algoritma ini mencari beberapa augmenting path sekaligus dalam sekali iterasi dengan meggunakan himpunan maksimal dari augmenting path terpendek.

Secara keseluruhan, algoritma ini berjalan pada sebuah grafik $G=\left(X \cup Y_{v} E\right)$, dimana $|V|$ adalah jumlah vertex yang berada pada $X \cup Y$ dan $|E|$ adalah jumlah edge pada grafik, dengan kompleksitas $O(|V| \sqrt{|E|)}$.

Dimisalkan terdapat sebuah grafik $G=\left(X \cup Y_{v} E\right)$ dan $M$ adalah matching yang di dapat dari grafik tersebut. Secara garis besar, algoritma ini berjalan sebagai berikut:

a. Sebuah breadth-first search digunakan untuk membagi vertex-vertex menjadi beberapa layer. Sebuah layer dalam hal ini diartikan sebagai sebuah level dalam tree, dan setiap level dalam tree menunjukkan panjang augmented path yang dapat di bentuk. Unmatched vertex pada $X$ digunakan sebagai vertex awal dari pencarian.

b. Pada awal pencarian, hanya terdapat unmatched edge dikarenakan $M$ masih merupakan himpunan kosong. Setelah itu, pada pencarian selanjutnya, melalui unmatched vertex pada $X$, pencarian path dilakukan dengan men-treverse unmatched edge dan matched edge secara bergantian. Pencarian akan berhenti pada sebuah layer-k dimana terdapat satu atau beberapa unmatched vertex pada $Y$ tercapai.

c. Setelah layer pada grafik tersebut terbentuk, melalui depth-first search, sebuah himpunan maksimal dari augmenting path terpendek yang memiliki panjang $k$ dapat dicari dengan awal unmatched vertex pada $X$ dan berakhir pada unmatched vertex $Y$.

d. Untuk setiap augmenting path yang ditemukan, semua unmatched vertex pada tersebut diubah menjadi matched vertex begitu pula sebaliknya.

Algoritma ini berakhir apabila pada proses pencarian breadth-first search tidak menemukan augmented path yang dapat dibentuk.

\section{STRATEGI PENYELESAIAN}

A. Menentukan waktu minimum penyelesaian semua pekerjaan ( $\alpha)$

Sesuai pada deskripsi masalah, dapat diketahui bahwa setiap orang harus mengerjakan semua pekerjaan yang ada sesuai dengan waktu penyelesainnya masing-masing dan setiap

\begin{tabular}{|l|l|l|}
\hline 2 & 2 & 4 \\
\hline 1 & 2 & 0 \\
\hline
\end{tabular}

(a)

\begin{tabular}{|l|l|l|l|l|}
\hline 2 & 2 & 4 & 0 & 0 \\
\hline 1 & 2 & 0 & 0 & 5 \\
\hline 5 & 0 & 0 & 3 & 0 \\
\hline 0 & 4 & 0 & 4 & 0 \\
\hline 0 & 0 & 4 & 1 & 3 \\
\hline
\end{tabular}

(b)

Gambar 2. Proses expanding-matrix (a) Matrix awal (b) Matrix selelah mengalami proses expanding-matrix

\section{B. Mencari maximum-size matching pada bipartite graph}

Secara umum algoritma yang digunakan untuk menyelesaikan permasalahan ini berjalan sebagai berikut:

a. Membentuk bipartite grafik $G=\left(X \cup Y_{s} E\right)$ dengan $X$ merupakan representasi dari kolom (pekerja) dan $Y$ merupakan representasi dari baris (pekerjaan) dari matrix yang baru. Sebuah edge pada $E$ menghubungkan vertex pada $X$ dan $Y$ apabila nilai $A_{i, j}$ pada matrix tersebut tidak 0 .

b. Mencari maximum matching yang terdapat pada grafik tersebut. Apabila sebuah kolom ${ }^{i}$ memiliki pasangan dengan baris $i$, artinya pekerja $\mathrm{ke}^{i}$ mengerjakan pekerjaan ke $-\bar{i}$ dalam suatu waktu tersebut. Apabila $j>m$ maka pekerja tersebut tidak melakukan pekerjaan apapun di satuan waktu tertentu.

c. Setiap baris $i$ dan $^{\text {kolom }}{ }^{i}$ yang berpasangan, kurangi nilai $A_{\mathrm{i}_{\tilde{L}} \tilde{j}}$ pada matrix tersebut sebanyak 1.

d. Ulangi setiap proses $1-3$ hingga matrix tersebut menjadi matrix dengan semua isinya adalah 0 .

Pada setiap proses yang terjadi, sebuah perfect matching terbentuk melalui grafik tersebut. Dikarenakan matrix adalah sebuah matrix persegi dengan ukuran $(m+n) *(n+m)$, maka semua baris memiliki pasangan pada kolom, begitu pula dengan kolom yang seluruhnya memiliki pasangan pada baris.

Seperti yang dijelaskan sebelumnya, diketahui bahwa jumlah dari semua elemen matrix tersebut adalah $(m+n) * a$ dan setiap kali proses jumlah dari matrix tersebut berkurang sebanyak $m+n$, maka total proses yang diperlukan untuk menjadikan matrix tersebut menjadi matrix 0 adalah tepat sebanyak $\alpha$.

\section{UJI COBA DAN ANALISIS}

\section{A. Uji Coba Kebenaran}

Uji coba kebenaran dilakukan dengan mengirimkan kode sumber program kedalam situs penilaian daring SPOJ dan melakukan perbandingan hasil keluaran dari sistem dengan permasalahan. Permasalahan yang diselesaikan yaitu Yet Another Assignment Problem dengan kode soal ASSIGN5.

Gambar 3. Hasil Uji Coba pada Situs SPOJ 
Kode sumber mendapat keluaran Accepted dari situs SPOJ. Hal ini berarti keluaran kode sumber telah sesuai dengan persoalan yang terdapat pada situs SPOJ. Waktu tercepat yang dibutuhkan program adalah 0.08 detik dan memori yang dibutuhkan adalah $64 \mathrm{MB}$.

Dilakukan pengujian sebanyak 20 kali pada situs penilaian daring SPOJ untuk melihat variasi waktu dan memori yang dibutuhkan program. Dari hasil uji coba sebanyak 20 kali, seluruh kode sumber program mendapat keluaran Accepted dengan waktu minimum sebesar 0.08 detik, waktu maksimum sebesar 0.12 detik dan waktu rata-rata sebesar 0.103 detik. Memori yang dibutuhkan program konstan sebesar $64 \mathrm{MB}$.

Tabel 1.

Hasil pengujian pada situs SPOJ sebanyak 20 kali

\begin{tabular}{cccc}
\multicolumn{4}{c}{ Hasil pengujian pada situs SPOJ sebanyak 20 kali } \\
\hline \hline ID & RESULT & TIME & MEM \\
\hline 17014913 & accepted & 0.08 & $64 \mathrm{M}$ \\
17014912 & accepted & 0.10 & $64 \mathrm{M}$ \\
17014910 & accepted & 0.10 & $64 \mathrm{M}$ \\
17014909 & accepted & 0.09 & $64 \mathrm{M}$ \\
17014906 & accepted & 0.11 & $64 \mathrm{M}$ \\
17014903 & accepted & 0.11 & $64 \mathrm{M}$ \\
17014901 & accepted & 0.09 & $64 \mathrm{M}$ \\
17014899 & accepted & 0.10 & $64 \mathrm{M}$ \\
17014898 & accepted & 0.11 & $64 \mathrm{M}$ \\
17014896 & accepted & 0.12 & $64 \mathrm{M}$ \\
17014895 & accepted & 0.11 & $64 \mathrm{M}$ \\
17014893 & accepted & 0.09 & $64 \mathrm{M}$ \\
17014891 & accepted & 0.11 & $64 \mathrm{M}$ \\
17014890 & accepted & 0.10 & $64 \mathrm{M}$ \\
17014889 & accepted & 0.11 & $64 \mathrm{M}$ \\
17014886 & accepted & 0.12 & $64 \mathrm{M}$ \\
17014883 & accepted & 0.11 & $64 \mathrm{M}$ \\
17014882 & accepted & 0.10 & $64 \mathrm{M}$ \\
17014879 & accepted & 0.10 & $64 \mathrm{M}$ \\
17011446 & accepted & 0.10 & $64 \mathrm{M}$ \\
\hline \hline
\end{tabular}

\section{B. Uji Coba Efisiensi Waktu}

Uji coba kinerja dilakukan dengan membuat data generator, untuk membangun contoh persoalan sesuai dengan batasan permasalahan. Kemudian dilakukan pembandingan kinerja program terhadap pertumbuhan jumlah pekerja dan pertumbuhan jumlah pekerjaan.

\section{1) Pengaruh Banyaknya Pekerjaan Terhadap Waktu}

Pada uji coba ini banyaknya pekerjaan dibuat bervariasi antara 1000 hingga 9000. Jumlah pekerja ditetapkan sebanyak 1000. Waktu eksekusi program dicatat dalam satuan.

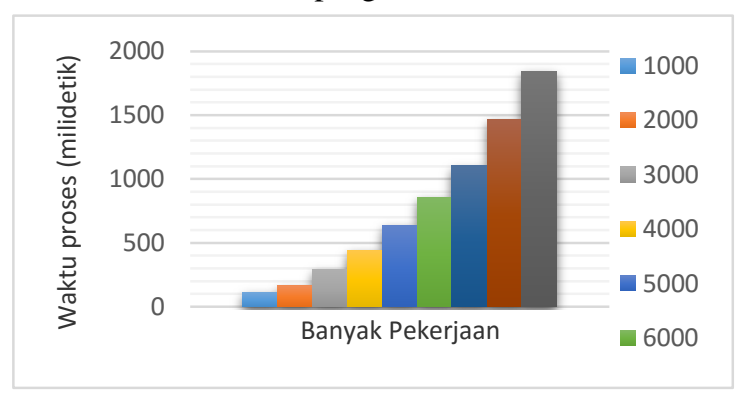

Gambar 4. Grafik Hasil Uji Coba Pengaruh Jumlah Pekerjaan Terhadap Waktu Eksekusi Program

Dapat dilihat bahwa grafik cenderung mendekati kurva kuadratik. Hal menunjukkan bahwa algoritma penyelesaian yang dipengaruhi secara kuadratik oleh jumlah pekerjaan.Pengaruh Banyaknya Pekerja Terhadap Waktu
Pada uji coba ini banyaknya pekerjaan dibuat bervariasi antara 1000 hingga 9000. Jumlah pekerja ditetapkan sebanyak 1000. Waktu eksekusi program dicatat dalam satuan.

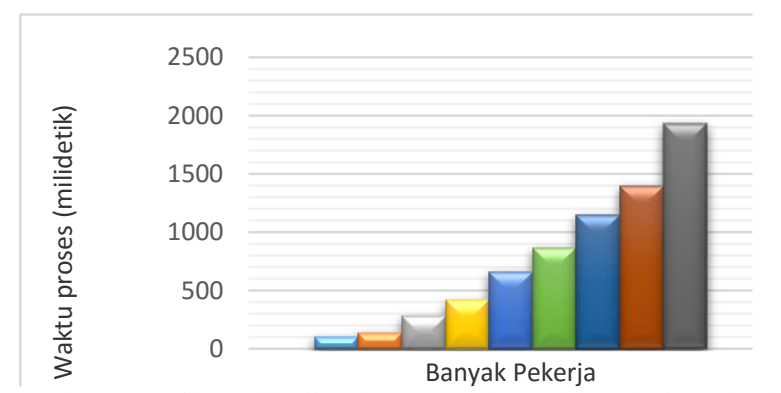

Gambar 5. Grafik Hasil Uji Coba Pengaruh Jumlah Pekerja Terhadap Waktu Eksekusi Program

Dapat dilihat bahwa grafik cenderung mendekati kurva kuadratik. Hal menunjukkan bahwa algoritma penyelesaian yang dipengaruhi secara kuadratik oleh jumlah pekerja.

\section{KESIMPULAN}

Dari hasil uji coba yang telah dilakukan terhadap implementasi penyelesaian permasalahan Yet Another Assigment Problem dapat diambil kesimpulan sebagai berikut:

1. Permasalahan Yet Another Assignment Problem pada situs SPOJ dapat direpresentasikan sebagai sebuah bipartite graph serta Implementasi algoritma HopcroftKarp dapat menyelesaikan permasalahan tersebut dengan benar.

2. Kompleksitas waktu yang dibutuhkan untuk seluruh proses sistem adalah $O\left((m+n)^{2}\right)$ pada $m$ buah pekerjaan dan $n$ orang pekerja sehingga algoritma ini dipengaruhi secara kuadratik baik oleh jumlah pekerja maupun jumlah pekerjaan.

\section{UCAPAN TERIMA KASIH}

Penulis mengucapkan terima kasih kepada Tuhan Yang Maha Esa atas segala karunia dan rahmat-Nya yang telah diberikan selama ini. Penulis juga mengucapkan terimakasih kepada orang tua, saudara, keluarga, Bapak Arya Yudhi Wijaya dan Bapak Rully Soelaiman selaku pembimbing penulis dan semua pihak yang tidak bisa penulis sebutkan satu persatu yang talah memberikan semangat serta motivasi sehingga penulis dapat menyelesaikan penelitian ini.

\section{DAFTAR PUSTAKA}

[1] SPOJ, "The dilemma of Idli," March 2014. [Online]. Available: http://www.spoj.com/problems/WPC5G/.

[2] S. Halim and F. Halim, "Competitive Programming 3," Singapore, Lulu Publisher, 2013.

[3] D. Jungnickel, Graphs, Networks and Algorithms, 4th Edition ed., Berlin: Springer, 2012.

[4] SPOJ, "Yet Another Assignment Problem," June 2010. [Online]. Available: http://www.spoj.com/problems/ASSIGN5/.

[5] J. Bondy and U. Murty, Graph Theory, 3rd ed., Berlin: Springer, 2008.

[6] H. A. Taha, Operations Research: An Introduction, 8th Edition ed., Upper Saddle River: Prentice Hall, 2007. 